\title{
Cone beam computed tomography for evaluation of impacted supernumerary teeth
}

\author{
Ahmed Fathi AL-Omar ${ }^{*}$ and Usama Abd El Raouf El Dakrory ${ }^{2}$ \\ ${ }^{1}$ Oral and Maxillofacial Surgery, Faculty of Oral and Dental Medicine, Cairo University, Egypt \\ ${ }^{2}$ Oral and Maxillofacial Surgery, Faculty of Oral and Dental Medicine, Misr University of science and technology, Egypt
}

\begin{abstract}
Background: Supernumerary paramolars are the rare anomalies of the maxillofacial complex. These are more common in the maxilla than in the mandible. Supernumerary teeth are an infrequent developmental alteration that can appear in any area of the dental arches and which are often associated with several syndromes such as cleidocranial dysplasia or Gardner syndrome. Multiple supernumerary teeth in individuals with no other associated diseases or syndromes are very uncommon.

Objective: To evaluate the value of cone-beam CT (CBCT) in the diagnosis and orientation of supernumerary teeth in the dental arches.

Treatment: After taking a cone beam computed tomograph (CBCT), surgical extraction was performed under local anaesthesia.

Conclusion: The position of the supernumerary teeth is varied in the maxilla, and often causes permanent dentition complications. CBCT imaging yields accurate 3-dimensional pictures of supernumerary teeth, local dental and bony structures, which is helpful for diagnosis and orientation of supernumerary teeth. Cone beam computed tomography is crucial for exact localization, for treatment planning, and for the surgical approach in cases of multiple supernumerary teeth.
\end{abstract}

\section{Introduction}

Supernumerary teeth are defined as those in addition to the normal series of deciduous or permanent dentition. They may occur anywhere in the mouth. They may appear as a single tooth or multiple teeth, unilaterally or bilaterally, erupted or impacted and in mandible/ maxilla or both the jaws. The prevalence of supernumerary teeth varies between 0.1 and $3.8 \%$ and is more common in the permanent dentition [1-3]. The low prevalence of supernumerary teeth in primary dentition is because it is generally overlooked by the parents, is often of normal shape (supplemental type), erupt normally, and appear to be in proper alignment [4]. Supernumerary teeth in the absence of syndromes such as cleidocranial dysplasia or Gardner's is a rare event. The most common supernumerary tooth is the mesiodens which appears in the maxillary midline. The exact etiology of supernumerary teeth is unclear but many theories exist in an attempt to explain why extra teeth are present in some individuals. Supernumerary teeth show strong association with developmental disorders such as cleft lip and palate, cleidocranial dysostosis, Gardener syndrome and less commonly with Ehlers-Danlos syndrome, Fabry Anderson's syndrome, chondroectodermal dysplasia [2]. Supernumerary teeth are classified according to morphology and location. Impacted supernumerary teeth may present as asymptomatic but can cause a plethora of clinical problems including, but not limited to: failure of eruption of teeth, displaced eruption of teeth, crowding, root resorption, cyst formation, incomplete space closure during orthodontic treatment and They may also interfere in alveolar bone grafting and implant placement [5-7]. The incidence is considerably higher in the maxillary incisor region followed by maxillary third molar and mandibular molar, premolar, canine and lateral incisors [8]. Though there is no significant sex distribution in primary supernumerary teeth, males are affected approximately twice than females in the permanent dentition [7,9].

\section{Diagnosis}

When supernumerary teeth are discovered and orthodontics employed, a decision regarding the fate of supernumerary teeth must be made. An important part of the decision process is determining the precise location of the supernumerary teeth. Because supernumerary teeth can cause delayed/impeded eruption of teeth, root resorption, and/ or inability to properly orthodontically move teeth into proper position, most supernumerary teeth should be removed prior to orthodontic treatment $[5,7]$. Prior to the development of three dimensional Cone Beam Computed Tomography (CBCT), determining the exact location of impacted supernumerary teeth could be approximated with multiple $\mathrm{x}$-rays from different angles. Distortion, projectional effects, and superimposition of adjacent structures often makes precise localization on the intended tooth difficult [5]. СBCT has been shown to provide superior three dimensional imaging to "plain films" and provide the doctor with precise anatomic truth in determining the location of impacted teeth $[5,6]$

\section{Case report}

The patient was referred to the Outpatient Clinic of Oral Surgery Department, Faculty of Oral and Dental Medicine, Cairo University from the Orthodontist Department for evaluation and treatment of impacted wisdom teeth as well as impacted supernumerary teeth in

Correspondence to: Ahmed Fathi AL-Omar, Oral and Maxillofacial Surgery, Faculty of Oral and Dental Medicine, Cairo University, Egypt; E-mail: ahmed_ alomar@hotmail.com

Key words: cone beam computed tomography, CBCT, supernumerary teeth

Received: July 29, 2017; Accepted: August 28, 2017; Published: August 31, 2017 
the left maxilla and mandible. Evaluation of the Panorex (Figure 1) shows supernumerary impacted teeth. Due to the inability to palpate either and the close proximity of these teeth to adjacent teeth and vital structures, a CBCT was ordered. Examination of the images from the CBCT shows the palatal location of tooth (Figure 2)

After discussion of the CBCT findings with the patient and parent, informed consent was obtained for extraction of the supernumerary teeth. Palatal approach was used to access and extract the supernumerary teeth (Figure 3).

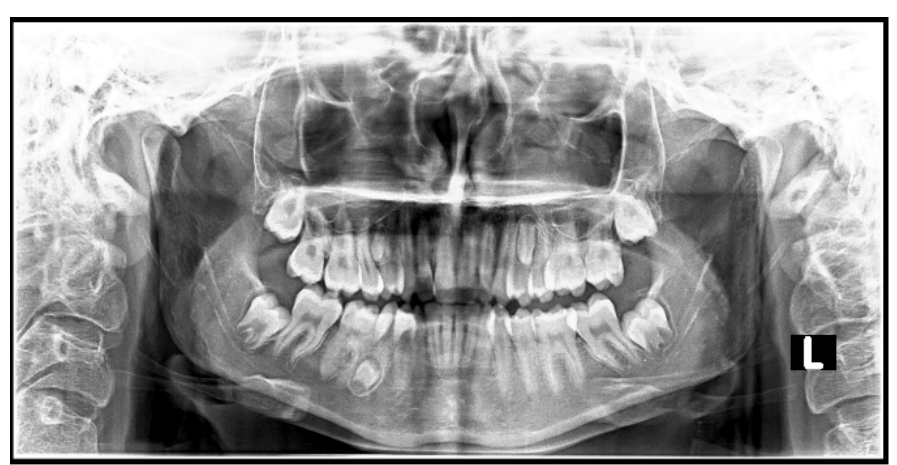

Figure 1. Panoramic view showing the supernumerary impacted teeth.

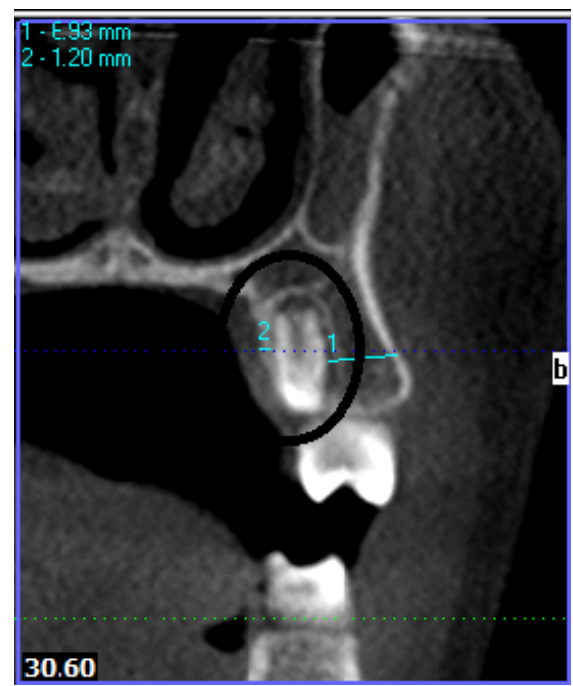

Figure 2. Examination of the images from the CBCT shows the palatal location of tooth.

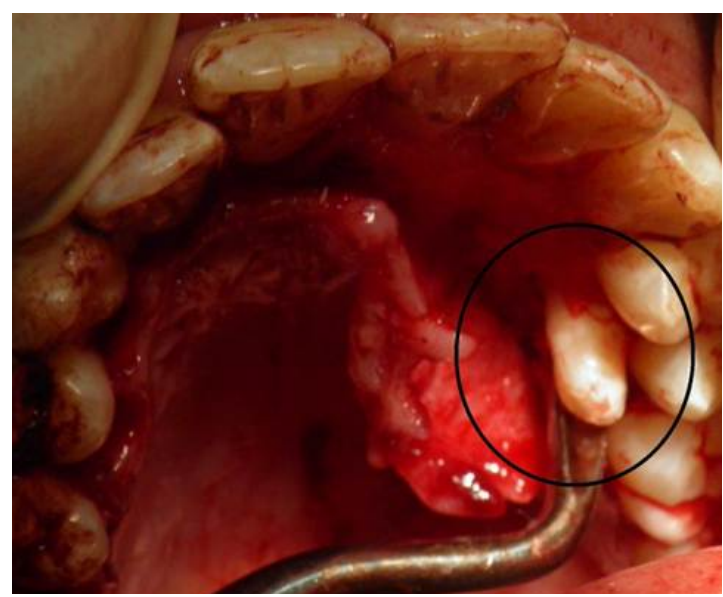

Figure 3: Palatal approach for extract the supernumerary teeth.
Extraction should be performed carefully to prevent damage to adjacent permanent teeth. The clinician should be careful to avoid complications such as damaging nerve and blood vessels during manipulation of the tooth, perforation of maxillary sinus, pterygomaxillary space, orbit and fracture of maxillary tuberosity.

\section{Discussion}

Correct surgical-orthodontic management of patients with impacted supernumerary teeth is enhanced by accurate diagnosis and precise localization of any supernumerary teeth.1 CBCT allows the surgeon and orthodontist to more accurately evaluate the exact location of supernumerary impacted teeth as well as assess their impact on the patient's orthodontic plan. Knowledge of the precise location of the supernumerary impacted teeth provides the surgeon with better diagnostic tools and thus allows him to better determine the risks and benefits of the surgery. This increased knowledge also translates into determination of better surgical approach when extracting the teeth and less risk to the patient.

\section{Conclusion}

The position of the supernumerary teeth is varied in the maxilla, and often causes permanent dentition complications. CBCT imaging yields accurate 3-dimensional pictures of supernumerary teeth, local dental and bony structures, which is helpful for diagnosis and orientation of supernumerary teeth. Cone beam computed tomography is crucial for exact localization, for treatment planning, and for the surgical approach in cases of multiple supernumerary teeth.

\section{References}

1. Yusof WZ (1990) Non-syndromal multiple supernumerary teeth: Literature review. $J$ Can Dent Assoc 56: 147-149. [Crossref]

2. Rajab LD, Hamdan MA (2002) Supernumerary teeth: Review of the literature and a survey of 152 cases. Int J Pediatr Dent 12: 244-254. [Crossref]

3. Brook AH (1974) Dental anomalies of number, form and size: Their prevalence in British school children. J Int Assoc Dent Child 5: 37-53. [Crossref]

4. Scheiner MA, Sampson WJ (1997) Supernumerary teeth: A review of the literature and four case reports. Aus Dent J 42: 160-165. [Crossref]

5. Brauer HU (2010) Case Report: Non-syndromic multiple supernumerary teeth localized by cone beam computed tomography. Eur Arch Paediatr Dent 11(1): 41-43. [Crossref]

6. Walker L, Enciso R, Mah J (2005) Three-dimensional localization of maxillary canines with cone-beam computed tomography. Am J Orthod Dentofacial Orthop 128(4): 418 23. [Crossref]

7. Garvey MT, Barry HJ, Blake M (1999) Supernumerary teeth-An overview of classification, diagnosis, and management. J Can Dent Assoc 65: 612-616. [Crossref]

8. Grimanis GA, Kyriakides AT, Spyropoulos ND (1991) A survey on supernumerary molars. Quintessence Int 22: 989-995. [Crossref]

9. Kinirons MJ (1982) Unerupted premaxillary supernumerary teeth. A study of their occurrence in males and females. Br Dent J 153: 110. [Crossref]

Copyright: (C2017 AL-Omar AF. This is an open-access article distributed under the terms of the Creative Commons Attribution License, which permits unrestricted use, distribution, and reproduction in any medium, provided the original author and source are credited. 